\title{
Laparoscopic Gastrostomy Placement in Children Has Few Major, but Many Minor Early Complications
}

\author{
Morten Kvello, Charlotte Kristensen Knatten, Kristin Bjørnland
}

\begin{abstract}
Introduction. Laparoscopic gastrostomy (LAPG) is an increasingly popular alternative to more traditional gastrostomy techniques. This study evaluates early postoperative com- plications following LAPG and investigates risk factors for gastrostomy complications.

Materials and Methods Retrospective study of patients $<16$ years undergoing LAPG from 2005 to 2018. Early postoperative complications ( $<30$ days) were grouped as gastrostomy-related or general and graded according to the Clavien-Dindo classification for surgical complications.

Results. A total of 104 patients, of which 54 (52\%) had neurological impairment (NI), were included. Median age and weight were 1.2 years ( 1 day-15.2 years) and $8.9 \mathrm{~kg}$ (3.4-36), respectively. Operating time was median 37 minutes (19-86) and shorter in the second half of the patients (46 vs. 35 minutes, $\mathrm{p} 1 / 40.04)$. A total of $40(38 \%)$ patients experienced 53 gastrostomy-related complications. Of these, seven complications needed surgical treatment; severe leakage (2), too short gastrostomy button (1), feeding difficulties (1), gastric outlet obstruction (1), omentum trapped in umbilical port sutures (1), and suspected fascial defect (1). Stoma infection and granulation tissue were reported in 13 and $12 \%$, respectively. Tube dislodgement occurred in six patients and was managed with bedside reinsertion in all. Gastrostomyrelated complications were less frequent in $\mathrm{NI}$ patients ( 46 vs $22 \%, p^{1 / 4} 0.01$ ).

Conclusion. LAPG is a safe procedure with few major complications, but a high rate of minor complications. Operating time declined during the study period, and NI patients had fewer gastrostomy-related complications.
\end{abstract}

\section{Introduction}

Gastrostomy insertions are one of the most common gastro- intestinal surgical procedures performed in pediatric patients. A gastrostomy can ensure long-term enteral nutrition in patients with a wide range of underlying diseases such as neurological impairment (NI) and congenital heart disease.1 Furthermore, gastrostomies may increase the quality of life in both patients and caregivers.2-5

The traditional open technique for gastrostomy insertion, which performed with a mini laparotomy, has largely been replaced by minimal invasive techniques. Most common is the percutaneous endoscopic gastrostomy (PEG) technique. 6 In recent years, gastrostomy insertion by laparoscopic technique (LAPG) has gained increasing popularity. A major advantage of LAPG compared with PEG is that it provides direct visualization

of the intra-abdominal cavity and thereby avoids inadvertent penetration of intra-abdominal organs. A recent meta-analysis found higher risk of adjacent bowel injuries after PEG than after LAPG.7 Furthermore, LAPG transfixes the stomach to the abdominal wall immediately postoperatively and thereby lowers the risk of operative treatment in case of accidental tube dislodgment in the early postoperative period. Lastly, LAPG allows direct insertion of a low-profile device, 8 which later can be replaced without the need for sedation or general anesthesia in contrast to several types of PEGs.9 Although LAPG has several advantages compared with PEGs, LAPG has higher costs and longer operating time.10,11

Even though LAPG has gained widespread use, there are still relatively few studies that have addressed the complication rate after LAPG. Therefore, the aim of this study was to describe our experience with LAPG over a 13-year period, and the primary objective was to report early postoperative complications after LAPG insertion. Furthermore, factors that might influence the complications rate were assessed. 


\section{Materials and Methods}

The present study is a retrospective, descriptive study of patients $<16$ years of age, undergoing LAPG at Oslo University Hospital, Rikshospitalet in the period from January 2005 to

February 2018. The hospital serves as regional hospital for around 2 million people in the eastern and southern parts of Norway, and children from the whole country (total population 5.3 million) may be referred for gastrostomy insertion if they need special anesthetic expertise. The patients were identified by an electronic search for the LAPG procedure in the hospital's database and crosschecked with data from a written surgical logbook. All patients were included, but patients undergoing insertion of PEG with laparoscopic assistance were excluded.

\section{Surgical Technique}

During the study period, the preferred technique for gastrostomy insertion has been PEG. Since its introduction, LAPG has increased in frequency and is performed mainly by surgeon's preference or if a PEG is considered inappropriate. This can for instance be due to previous upper abdominal surgery or radiologic or clinical findings suggesting that either bowel or

liver may preclude a safe PEG insertion.12 The LAPG procedures were performed by either two consultants or one junior doctor supervised by a consultant. A 5-mm camera was placed through the umbilicus using an open technique. Under direct visualization, a 5-mm trocar was inserted in the upper left quadrant at the site for the gastrostomy. Care was taken to not place the gastrostomy too close to the costal margin. The stomach was grabbed at a suitable site on the anterior wall, preferably close to the lesser curvature in the angulus region and then exteriorized by pulling out the trocar and grasper for suturing and insertion of the gastrostomy tube. The technique for suturing the stomach to the abdominal wall varied some- what. The U-stich method was done as described in detail by Backman and coworkers.13 Briefly, with grasper holding the stomach wall, one absorbable suture was placed through the abdominal wall $0.5 \mathrm{~cm}$ from the gastrostoma, then through the stomach wall, and the abdominal wall on the opposite side

$0.5 \mathrm{~cm}$ from the gastrostoma. The suture was pulled out and turned 180 degrees, and the same procedure was done in the opposite direction. By this technique using two continuous U-stiches forming a purse string suture around the gastro- stoma, the stomach was fixated to the abdominal wall at the same time. In the purse string method, the opening in the stomach wall was closed with a purse string absorbable suture, and the stomach was then sutured to the fascia with four interrupted absorbable sutures.14 For both methods, the stomach was opened using diathermia after the stomach had been fixated and the purse string sutures been placed. There was no use of T-fasteners for gastropexy in our study. Usually, a low-profile button was inserted, if not, a balloon gastrostomy tube was placed. In all patients, one dose of prophylactic antibiotics was given after the induction of anesthesia.

\section{Collection of Data}

Patient data were obtained retrospectively from electronic medical records. Demographic data included age, sex, weight, and underlying diagnosis; most likely contributing to the patients' feeding problems. NI was defined as a static or progressive, central or peripheral neurologic condition associated with chronic functional or intellectual impairment,15 for example, cerebral palsy, quadriplegia, and genetic syndromes. Operating time, perioperative complications, and any concomitant procedure were recorded. Operating time was only registered in patients who did not have other surgical procedures performed at the same time. One patient received a gastrojejunal tube with endoscopic assistance, and this patient was excluded when registering operating time.

Postoperative complications during the first 30 postoperative days were recorded, including both gastrostomy-related (e.g., stoma infection, leakage, and tube dislodgment) and nongastrostomyrelated complications (e.g., pneumonia and dehydration). In patients with a concomitant procedure, 
non- gastrostomy-related complications were excluded. The com- plications were graded according to the Clavien-Dindo classification for surgical complications.16 Risk factors for

gastrostomy-related complications including $\mathrm{NI}$ versus non- $\mathrm{NI}$, age under and over 1 year, and size of gastrostomy tube were investigated. Furthermore, rates of gastrostomy-related complications in patients operated by junior doctors and consultants were compared, as well as changes over time.

Ethical Approval

The study has approval from the hospital's Institutional Review Board (2016/43).

\section{Statistics}

Patient data were presented with descriptive statistics; frequencies and percentages and median and range (as data were not normally distributed). Operating time in the first and second half of patients, as well as between junior doctors and consultants, were compared using the Mann-Whitney'sU test as data were not normally distributed. The Chi-squared test was applied when investigating risk factors for gastrostomy-related complications, including NI-status, tube size, and age. Patients having 16 french gauge $(\mathrm{Fr})$ tubes inserted were excluded from this risk factor analysis due to low numbers. Age was transformed into dichotomous variables when comparing rates of gastrostomy-related complications, and the Chi-squared test was applied. All analyses were performed by IBM SPSS software for Windows version 25.0 (IBM Corp, Armonk, NY). p-values $<0.05$ were considered statistically significant.

\section{Results}

During the study period, 104 patients were identified, of whom 60 (58\%) were females. The median age and weight at operation were 1.2 (1 day-15.2 years) years and 8.9 (3.4-36) kg, respectively. The most common underlying diagnosis was $\mathrm{NI}(\mathrm{n} 1 / 454 ; 52 \%)$, followed by congenital anomalies including heart defects ( $n 1 / 424 ; 23 \%)$, respiratory disease ( $n 1 / 47 ; 7 \%)$, malignancy

(n $1 / 46 ; 6 \%)$, and others (n $1 / 413,13 \%)$.

\section{Perioperative Data}

Junior doctors operated 48 (46\%) patients. A low-profile button or a balloon tube was inserted in 65 $(63 \%)$ and 29 (28\%) patients, respectively. In nine (9\%) patients, a Malecot's catheter was used.

Finally, one patient got a gastrojejunal tube. The size of tubes inserted was $12 \mathrm{Fr}$ in 27 (26\%) patients, $14 \mathrm{Fr}$ in $69(66 \%)$ patients, and $16 \mathrm{Fr}$ in six (6\%) patients. Data on tube size were missing in the final two patients. The purse string method was used in $79(76 \%)$ patients and the U-stitch method in the remaining 25 (24\%) patients. In 19 (18\%) patients, one or more interrupted sutures was placed to downsize the stoma channel opening. Of these, six had $12 \mathrm{Fr}$ tubes and 13 had $14 \mathrm{Fr}$ tubes inserted. Concomitant procedures were performed in 34 (33\%) patients; most commonly laparoscopic repair of inguinal hernia ( $n$ 1 1/4 12) and laparoscopic Nissen fundoplication ( $n$ 1/4 6). Perioperative complications occurred in two (2\%) patients. In one patient, a mini laparotomy was performed because the nasogastric tube had fastened in the purse string suture. In the second patient, one of the ports caused a minor liver hemorrhage that was treated conservatively. This was the patient in whom a gastrojejunal tube was inserted.

For patients where no concomitant procedures were per-formed, the median operating time was 37 (19-86) minutes (n $1 / 465$, missing $1 / 4$ 4). When comparing operating time in the first and second time period, median operating time was significantly shorter in the latter time period (46 vs. 35 minutes, $\mathrm{p} 1 / 40.04)$. Median operating time was not different between junior doctors and consultants (36 vs. 40 minutes, $p^{1 / 4} 0.3$ ).

Postoperative Complications

During the first 30 postoperative days, 53 gastrostomy-related complications occurred in 40 (38\%) patients (Table 1). Non- NI patients had a significantly higher rate of gastrostomy- related complications compared with $\mathrm{NI}$ patients ( $46 \mathrm{vs.} 22 \%$, $\mathrm{p} 1 / 40.01$ ). We could not demonstrate any 
significant difference in gastrostomy-related complication rates between patients under and over 1 year ( 35 vs. $32 \%, \mathrm{p} 1 / 40.7$ ). There was no difference in gastrostomy-related complications between patients having a 12 or $14 \mathrm{Fr}$ tube inserted (44 vs. 30\%, p 1/4 0.19). Furthermore, whether a junior doctor or a consultant performed the operation did not seem to influence the complication rate (35 vs. $32 \%, \mathrm{p} 1 / 40.7)$. Finally, rates of gastrostomy-related complications were not significantly different when comparing the patients in the first and second half of the time period ( $37 \mathrm{vs.} 31 \%, \mathrm{p} 1 / 40.5$ ). Complications, which were not directly related to the gastrostomy, were only recorded in the 70 patients who did not undergo a concomitant surgical procedure. Eight (11\%) patients experienced nongastrostomy-related complications. These included three grade I complications (dehydration, 2 and urinary retention1), two grade II complications (bronchiolitis1 and pneumonia1), one grade IIIb complication (postoperative VP- shunt failure needing operative management), and two grade IV complications (multiorgan failure due to bronchiolitis,1 pneumonia needing mechanical ventilation1).

\section{Discussion}

This paper describes early complications after LAPG in a large population of patients treated at a tertiary pediatric referral center. The study shows that LAPG is a safe procedure with few severe complications, but minor complications are common.

\section{Major Complications}

Gastrostomy-related complications necessitating intervention under general anesthesia occurred in $6 \%$ of the patients in this study. In previous reports, the rate of major complications varies from 0 to $9 \% .11,17,18$ Since major complications have somewhat different definitions in various studies, it is difficult to compare exact numbers.

Details and treatment consequences of major complications are often not reported in the literature, and ways to avoid such complications are therefore rarely discussed. Gastric outlet obstruction from the balloon is a complication that has been reported in previous studies 19,20 and occurred in three patients in the current study. In two patients, this could be handled by tightening the gastrostomy tube, while the third patient had to undergo a laparotomy. During the operation, it was noted that the tube was placed too close to the pylorus. Although this complication is rare, surgeons must take particular care when choosing the place in the stomach wall for the gastrostomy to not put it too close to the pylorus.

Two of the grade IIIb complications were specific to laparoscopy; omentum trapped in umbilical port sutures and suspected fascial defects. Port site hernia is a well-known complication after laparoscopy, and a study of 461 pediatric patients undergoing LAPG, reported port site hernia in $0.7 \%$ of the patients. 20

A surprising finding in this study is that leakage from the gastrostomy site was so severe in two patients that enteral nutrition had to be stopped and central venous access for parenteral nutrition was necessary. Leakage is a commonly reported complication after LAPG insertion,21,22 but most can be handled conservatively by adjustment of the gastrostomy device or temporary stop of feeds. However, leakage has been reported to necessitate surgical revision of the gastrostomy but mostoften late after insertion.18,20,23 Possible causes of leakage after LAPG are too wide incisions and inflammation around the sutures fixating the stomach to the abdominal wall. When comparing 14 and $12 \mathrm{Fr}$ button devices, Sjövie et al found higher rates of leakage in patients undergoing LAPG with a $14 \mathrm{Fr}$ button device, suggesting that the size of the gastrostomy also may influence leakage. 24 In our study, both 12 and $14 \mathrm{Fr}$ devices were used, and we found no difference in gastrostomy-related complications between these two groups of patients. Perioperative conversion from laparoscopy to laparotomy is reported in some series listing operative results after LAPG. Rates of conversion are low (0.7-4.8\%) and the most common reason for conversion is previous abdominal surgery.11,18,25 In this series, there were no perioperative conversions to laparotomy. The low conversion rate may be explained by patient selection, as patients having undergone previous major upper abdominal surgery, were not offered LAPG. 
Gastric prolapse and intraperitoneal leak needing surgical treatment have been reported to occur early after LAPG.11,23 We did not experience any of these complications. To avoid gastric prolapse, it is important that the gastrostomy channel is not too wide and to have a perfect length of the button or a firm fixation of the gastrostomy tube. The stoma nurses at our department are very meticulous in their follow-up of patients getting LAPG. It is possible that their follow-up has been important for omitting these complications.

A major advantage of LAPG is direct visualization of intra- abdominal organs, and in line with other studies, 26 we had no incidence of perforation of colon or other intra-abdominal organs after LAPG. A meta-analysis of studies comparing LAPG and PEG found a higher risk for this specific complication after PEG insertion.7

\section{Minor Complications}

Minor complications, usually defined as not needing surgical management or intensive pharmacological treatment, are commonly observed after allgastrostomy techniques. Although minor complications are not life threatening, they are a significant cause for distress for both patients and caregivers and lead to increased health care utilization. 27 In two large studies on LAPG, minor complications occurred in as many as 74 and $63 \%$ of the patients.11,18 In our study, grade I and II complications were recorded in $44 \%$ of patients. Stoma infection and granulation tissue were the two most common minor complications, reported in 13 and $12 \%$, respectively. In a study of 300 pediatric patients with a median follow-up time of 2.6 years, stoma infections were reported in $25 \%$ and granulation tissue in $44 \%$ of patients. 18 The lower numbers in our study are probably because complications were only registered during the first postoperative month.

\section{Tube Dislodgement}

Early tube dislodgment is a feared complication after gastrostomy insertion because the stoma channel takes some weeks to heal. In a meta-analysis comparing PEG and LAPG, early dislodgment was less frequent after LAPG and when early dislocation occurs after PEG, patients often need management under general anesthesia to safely reinsert the tube.7 In our series, there were six tube dislodgements, but all could be handled with bed side reinsertion without need for general anesthesia. This may be considered an important advantage of LAPG.

\section{Risk Factors}

Because complications after gastrostomy insertion are com- mon, several studies have tried to identify risk factors for complications. Interestingly, age, weight, or NI did not seem to influence complication rate in most studies looking at risk factor for complications11,20,28 There is, though, one study by Liu et al that found that $\mathrm{NI}$ was a risk factor for both early and late complications. 29 Contrary to this, we found lower rates of gastrostomy-related complications in NI patients. There is heterogeneity within the group of NI patients, and numbers are low so no firm conclusions should be made. It is possible that caregivers of $\mathrm{NI}$ patients are used to handling medical equipment and therefore better at managing the gastrostomy tube than caregivers of other patient groups and thereby having less problems with the gastrostomy.

Age under 1 year was not found to be a risk factor in our study, and this is in line with others suggesting that LAPG is safe also in the smaller patients.30,31 Still, we would question whether it is wise to use gastrostomy buttons in newborns. In this series, a 1-day-old baby with long gap esophageal atresia who had a balloon device inserted experienced severe leakage.

The stomach was very small as usual in these patients, and the balloon filled most of the lumen in the stomach. It is very plausible that this has contributed to the leakage when feeding started. Therefore, for this particular patient group, the placement of a Malecot's catheter is probably a better alternative. Furthermore, it is also our experience that LAPG is more difficult to place in obese patients with a thick abdominal wall and abundant subcutaneous fat. In line with our experience, 
Rothenberg et al suggest the insertion of PEG underdirect laparoscopic visualization in obese patients. 8

\section{Learning Curve of LAPG Insertion}

In the literature, a major disadvantage of LAPG is longer operating time than after PEG. Studies report median operating time up to 75 minutes.21 The median operating timefor LAPG in this study was 38 minutes, which is comparable to Liu et al's series on 260 patients. They reported a mean operating time of 35 minutes. 29 One of our patients had a particularly long operating time of 86 minutes. In this patient, the stomach was sutured to the abdominal wall by intracorporeal suturing. During the study period, we found that operating time decreased-suggesting a learning curve for the team. There are other centers reporting shorter operating time than us, and in these centers LAPG is the preferred technique. Backman et al.

and Rothenberg et al. report a mean operating time of 22 and 15 minutes, respectively.8,13 This further supports our assumption that operating time can decrease with experience.

In contrast to decrease in operating time during the study period, we did not find a decrease in gastrostomy-related complications. A high number of surgeons performed the procedure. LAPG is a procedure with several potential pit- falls, and it is possible that lowering the number of surgeons could reduce the complication rate. At the same time, we did not find that patients operated by junior doctors had more complications than those operated by consultant. Since gastrostomy is a commonly performed procedure, it is important that several surgeons can manage the procedure, and we think this a procedure that is well suited for junior doctors to acquire laparoscopic skills.

\section{Choosing Gastrostomy Technique}

Over the years, several attempts have been made to improve the LAPG technique and to avoid both major and minor complications.13,32 Although studies suggest fewer complications after LAPG compared with PEG, no randomized controlled trials have been performed and there is no consensus on preferred technique. Gastrostomy insertion, both LAPG and PEG, remains a procedure with a significant risk for complications, and physicians should take into consideration the patients' comorbidity and procedure-related risk when choosing technique.

Strengths, Weaknesses, and Generalizability

The current study is limited by its retrospective nature and follow-up time of only 30 days. The rate of complications could be underestimated, as especially minor complications can be managed at local hospitals or by general practitioners, and many complications occur after the first postoperative month. As our institution is a tertiary referral center, patients in this study may have more severe underlying conditions and higher anesthesia-related risk. Strengths of this study include the fact that all patients undergoing LAPG over a 13-year long period were included. Furthermore, we included all complications, not only gastrostomy related, and graded complications according to a well-known classification system based on how the complications were handled. Since nurses document clinical findings three times daily in the medical records, it is unlikely that any complication occurring at the hospital has been missed. Furthermore, the stoma nurses inform all care- givers pre and postoperatively, and the parents get the nurses' phone number if the need to contact them. All such telephone consultations are documented in the electronic patient files. Thus, it is unlikely that many complications during the first month have been missed.

Conflict of Interest

None declared.

\section{Acknowledgment}

The authors thank stoma nurses, Astrid Austrheim and Hanne Ambrose (Oslo, Norway), for their work on patient follow-up and medical record documentation. We also thank pediatric surgeon, Kjetil Ertresvåg (Oslo, Norway) for comments on study planning and the final manuscript. 
References

1 Braegger C, Decsi T, Dias JA, et al; ESPGHAN Committee on Nutrition. Practical approach to paediatric enteral nutrition: a comment by the ESPGHAN committee on nutrition. J Pediatr Gastroenterol Nutr 2010;51(01):110-122

2 McSweeney ME, Jiang H, Deutsch AJ, Atmadja M, Lightdale JR. Long-term outcomes of infants and children undergoing percu- taneous endoscopy gastrostomy tube placement. J Pediatr Gastro- enterol Nutr 2013;57(05):663-667

3 Sullivan PB, Juszczak E, Bachlet AM, et al. Impact of gastrostomy tube feeding on the quality of life of carers of children with cerebral palsy. Dev Med Child Neurol 2004;46(12):796-800

4 Pemberton J, Frankfurter C, Bailey K, Jones L, Walton JM. Gastro- stomy matters-the impact of pediatric surgery on caregiver quality of life. J Pediatr Surg 2013;48(05):963-970

$5 \quad$ Avitsland TL, Kristensen C, Emblem R, Veenstra M, Mala T, Bjørnland K. Percutaneous endoscopic gastrostomy in children: a safe technique with major symptom relief and high parental satisfaction. J Pediatr Gastroenterol Nutr 2006;43(05):624-628

6 Gauderer MW, Ponsky JL, Izant RJ Jr. Gastrostomy without lapa- rotomy: a percutaneous endoscopic technique. J Pediatr Surg 1980;15(06):872-875

7 Suksamanapun N, Mauritz FA, Franken J, van der Zee DC, van Herwaarden-Lindeboom MY. Laparoscopic versus percutaneous endoscopic gastrostomy placement in children: results of a systematic review and meta-analysis. J Minim Access Surg 2017;13(02):81-88

8 Rothenberg SS, Bealer JF, Chang JH. Primary laparoscopic place- ment of gastrostomy buttons for feeding tubes. A safer and simpler technique. Surg Endosc 1999;13(10):995-997

9 Petrosyan M, Khalafallah AM, Franklin AL, Doan T, Kane TD. Laparoscopic gastrostomy is superior to percutaneous endoscop-ic gastrostomy tube placement in children less than 5 years of age. J Laparoendosc Adv Surg Tech A 2016;26(07):570-573

10 Lee $\mathrm{H}$, Jones $\mathrm{A}$, Vasudevan $\mathrm{S}$, et al. Evaluation of laparoscopic- assisted percutaneous gastrostomy tube placement in children. Pediatr Endosurg Innov Tech 2002;6:29-32

11 Akay B, Capizzani TR, Lee AM, et al. Gastrostomy tube placement in infants and children: is there a preferred technique? J Pediatr Surg 2010;45(06):1147-1152

12 Kvello M, Åvitsland TL, Knatten CK, et al. Trends in the use of gastrostomies at a tertiary paediatric referral centre. Scand J Gastroenterol 2016;51(05):625-632

13 Backman T, Sjövie H, Kullendorff CM, Arnbjörnsson E. Continuous double U-stitch gastrostomy in children. Eur J Pediatr Surg 2010; 20(01):14-17

14 Zamakhshary M, Jamal M, Blair GK, Murphy JJ, Webber EM, Skarsgard ED. Laparoscopic vs percutaneous endoscopic gastro- stomy tube insertion: a new pediatric gold standard? J Pediatr Surg 2005;40(05):859-862

15 Berry JG, Poduri A, Bonkowsky JL, et al. Trends in resource utilization by children with neurological impairment in the United States inpatient health care system: a repeat cross-sectional study. PLoS Med 2012;9(01):e1001158

16 Dindo D, Demartines N, Clavien PA. Classification of surgical com- plications: a new proposal with evaluation in a cohort of 6336 patients and results of a survey. Ann Surg 2004;240(02):205-213 17 Merli L, De Marco EA, Fedele C, et al. Gastrostomy placement in children: percutaneous endoscopic gastrostomy or laparoscopic gas- trostomy? Surg Laparosc Endosc Percutan Tech 2016;26(05):381-384

18 Franken J, Mauritz FA, Suksamanapun N, Hulsker CC, van der Zee DC, van HerwaardenLindeboom MY. Efficacy and adverse events of laparoscopic gastrostomy placement in children: results of a large cohort study. Surg Endosc 2015;29(06):1545-1552

19 Jones VS, La Hei ER, Shun A. Laparoscopic gastrostomy: the preferred method of gastrostomy in children. Pediatr Surg Int 2007;23(11):1085-1089 
20 Aprahamian CJ, Morgan TL, Harmon CM, Georgeson KE, Barnhart DC. U-stitch laparoscopic gastrostomy technique has a low rate of complications and allows primary button placement: experience with 461 pediatric procedures. J Laparoendosc Adv Surg Tech A 2006;16(06):643-649 21 Wragg RC, Salminen H, Pachl M, et al. Gastrostomy insertion in the 21st century: PEG or laparoscopic? Report from a large single- centre series. Pediatr Surg Int 2012;28(05):443-448

22 Angsten G, Danielson J, Kassa AM, Lilja HE. Outcome of laparo- scopic versus open gastrostomy in children. Pediatr Surg Int 2015; 31(11):1067-1072

23 Conlon SJ, Janik TA, Janik JS, Hendrickson RJ, Landholm AE. Gastrostomy revision: incidence and indications. J Pediatr Surg 2004;39(09):1390-1395

24 Sjövie H, Larsson LT, Arnbjörnsson E. Postoperative gastrostomy site leakage correlated to the dimension of the gastrostomy button in children. Gastroenterol Insights 2010;2:34-36

25 Norén E, Gunnarsdóttir A, Hanséus K, Arnbjörnsson E. Laparoscopic gastrostomy in children with congenital heart disease. J Laparoen- dosc Adv Surg Tech A 2007;17(04):483-489

26 Lantz M, Hultin Larsson H, Arnbjörnsson E. Literature review comparing laparoscopic and percutaneous endoscopic gastro- stomies in a pediatric population. Int J Pediatr 2010;2010:507616 27 Naiditch JA, Lautz T, Barsness KA. Postoperative complications in children undergoing gastrostomy tube placement. J Laparoen- dosc Adv Surg Tech A 2010;20(09):781-785

28 Viktorsdottir $M$, Salö $M$, Stenström $P$, et al. Complications accord- ing to underlying disease in children undergoing video-assisted gastrostomy. Med Res Arch 2017;5:1-12

29 Liu R, Jiwane A, Varjavandi A, et al. Comparison of percutaneous endoscopic, laparoscopic and open gastrostomy insertion in children. Pediatr Surg Int 2013;29(06):613-621

30 Backman T, Arnbjörnsson E, Berglund Y, Larsson LT. Video- assisted gastrostomy in infants less than 1 year. Pediatr Surg Int 2006;22(03):243-246

31 Kozlov Y, Novozhilov V, Kovalkov K, Rasputin A, Baradieva P, Razumovsky A. Comparison of the laparoscopic and open meth- ods of gastrostomy at neonates and infants up to three months of age. J Laparoendosc Adv Surg Tech A 2019;29(07):958-964

32 Mason CA, Skarda DE, Bucher BT. Outcomes after laparoscopic gastrostomy suture techniques in children. J Surg Res 2018; 232:26-32 


\section{Table 1}

Gastrostomy-related complications, graded according to the Clavien-Dindo classification for surgical complications, during the first 30 postoperative days after laparoscopic gastrostomy insertion in 104 pediatric patients.

\begin{tabular}{|l|l|}
\hline Number of complications & 53 \\
\hline Grade I & 40 \\
\hline Granulation tissue & 13 \\
\hline Stoma infection & 8 \\
\hline Leakage & 6 \\
\hline Tube dislodgement a) & 6 \\
\hline Bleeding & 3 \\
\hline Gastric outlet obstruction & 2 \\
\hline Detached skin sutures & 1 \\
\hline Tube blockage & 1 \\
\hline Grade II & 6 \\
\hline Stoma infection & 6 \\
\hline Grade Illb & 7 \\
\hline Leakage b) & 2 \\
\hline Short gastrostomy button c) & 1 \\
\hline Feeding difficulties d) & 1 \\
\hline Gastric outlet obstruction e) & 1 \\
\hline Omentum trapped in umbilical port & 1 \\
sutures f) & \\
\hline Suspected fascial defect g) & 1 \\
\hline
\end{tabular}

a) Six tube dislodgments occurred in four patients; two had a balloon tube inserted and two a low profile balloon button.

b) Patients where leakage made it impossible to use the gastrostomy and a central venous line was necessary to ensure parenteral nutrition.

c) Patient with severe postoperative pain and suspicion of short gastro- stomy button. This was confirmed and managed with laparotomy and insertion of a new button.

d) Patient with postoperative discomfort and vomiting related to tube feeding. A central venous line was necessary to ensure parenteral nutrition.

e) Patient with postoperative vomiting, where a contrast X-ray exami- nation showed that the balloon tube caused gastric outlet obstruction. Managed with laparotomy and insertion of a new tube.

f) Postoperative suspicion of omentum trapped in fascial sutures in umbilical port, which was confirmed and managed with a procedure under general anesthesia.

g) Patient with a peritoneal dialysis catheter, whom 2 weeks postopera-

tive presented with abdominal subcutaneous swelling. Contrast $\mathrm{X}$-ray examination (through peritoneal dialysis catheter) showed suspicion of a fascial defect in relation to the location of a laparoscopic port. A laparoscopic procedure was performed, showing only a defect in the peritoneum, which was sutured. 